\title{
Self-Reported Medication Use among Adolescents in Kuwait
}

\author{
Eman Abahussain $^{\mathrm{a}}$ Lloyd K. Matowe $^{\mathrm{a}}$ P.J. Nicholls ${ }^{\mathrm{b}}$ \\ ${ }^{a}$ Department of Pharmacy Practice, Faculty of Pharmacy, Kuwait University, Kuwait; ${ }^{b}$ Welsh School of Pharmacy, \\ Cardiff University, Cardiff, UK
}

\section{Key Words}

Self-medication - Adolescents - Gender differences • Age differences $\cdot$ Kuwait

\begin{abstract}
Objective: The objectives of this study were to describe and examine the pattern of medication use, including age and gender differences among adolescents in $\mathrm{Ku}$ wait, and to establish the sources of information on medicines in this age group. Subjects and Methods: A crosssectional survey of 1,110 male and female students (14-21 years) from 10 randomly selected public schools in Kuwait was conducted. The prevalence of self-medication was estimated. Results: The prevalence of self-medication among the high school students was $92 \%$. The prevalence increased by age from $87 \%$ among 14-yearolds to $95 \%$ among 18 -year-olds. Sixty-five percent of medicines used were for pain relief, $54 \%$ for respiratory conditions, 39\% for allergic conditions, and 37\% for dermatological conditions. Twenty-two percent of medicines were nutritional supplements and vitamins, $21 \%$ gastrointestinal products, $17 \%$ antidandruff products, $15 \%$ hair products, $13 \%$ for migraine while $8 \%$ were for athlete's foot. Pain relief, respiratory, dermatologic and hair products were more prevalent in female adolescents than in male while antidandruff and athlete's foot preparations were used more by male adolescents. The most common sources of information on medicines were parents. Conclusion: The prevalence of self-medication among adolescents in Kuwait is high. Self-medication
\end{abstract}

tended to increase with age and differed between male and female students. Few students consulted pharmacists for information on drugs. There is need to promote the image of the pharmacist in Kuwait as a provider of medication information.

Copyright (C) 2005 S. Karger AG, Basel

\section{Introduction}

Internationally, self-medication has been reported as being on the rise [1-3]. Self-medication is defined as the use of medication by a patient on his own initiative or on the advice of a pharmacist or a layperson instead of consulting a medical practitioner [4]. In 1999, the American Pharmaceutical Association estimated that, of the 3.5 billion health problems treated in the USA annually, 57\% were treated with a non-prescription drug [5]. The World Health Organization has emphasised that self-medication must be correctly taught and controlled [1].

In Kuwait, it is suspected that the prevalence of selfmedication is high. One reason for this may be related to the availability of a wide range of non-prescription medication that can be obtained from community pharmacies without a doctor's prescription, with the notable exception of antibiotics, narcotic analgesics, steroids and major tranquillisers. Another reason could be the influence of peers and parents. A number of studies have reported that self-medication starts with the onset of adolescence and increases with age [6, 7]. 
The present study describes the pattern of self-medication and evaluates the effect of age and gender on these patterns in a randomly selected group of adolescents in Kuwait. In addition, we sought to establish the sources of information on medicines in this age group.

\section{Subjects and Methods}

A cross-sectional study was conducted among 1,110 secondary school students in 10 government schools in Kuwait. The students were in grades 9-12, age 14-21 years (mean age 16.23 years); 601 were male and 509 female. Five girls' schools and five boys' schools were randomly selected. Clusters (classes) were selected randomly from these schools. Anonymous self-administered questionnaires were distributed to the students and completed during a regular

Table 1. Baseline characteristics of participants

\begin{tabular}{lrrrrr}
\hline \multirow{2}{*}{ Age, years } & \multicolumn{2}{c}{ Male $(\mathrm{n}=601)$} & & \multicolumn{2}{c}{ Female $(\mathrm{n}=509)$} \\
\cline { 2 - 3 } \cline { 6 - 7 } & $\mathrm{n}$ & $\%$ & & $\mathrm{n}$ & $\%$ \\
\hline 14 & 53 & 8.8 & & 74 & 14.6 \\
15 & 118 & 19.6 & & 78 & 15.4 \\
16 & 155 & 25.8 & & 132 & 26.0 \\
17 & 169 & 28.2 & & 165 & 32.5 \\
18 & 85 & 14.2 & & 47 & 9.3 \\
Over 19 & 19 & 3.2 & & 11 & 2.2 \\
\hline Nationality & & & & \\
$\quad$ Kuwaiti & 594 & 98.8 & & 490 & 96.5 \\
$\quad$ Non-Kuwaiti & 7 & 1.2 & & 18 & 3.5 \\
\hline
\end{tabular}

class period. Students answered questions relating to the use of nonprescribed medications over the preceding year.

Questions were mainly closed multiple choice type. The questionnaire was divided into three main sections that elicited responses on: (i) socio-demographic characteristics: gender, age, nationality, education level; (ii) aspects of self-medication: the type of the medicines, reasons for use, and (iii) sources of information about medications.

The coded data were analysed using the Statistical Package for Social Sciences (SPSS) V.11. The prevalence of self-medication was determined as percentage of users out of the total sample. Chisquared tests were used to compare the prevalence of medication use between males and females, between age groups and to test for association between two categorical variables. The $p$ values calculated were two-tailed, and $\mathrm{p} \leq 0.05$ was considered significant.

\section{Results}

\section{Baseline Characteristics of Participants}

Baseline characteristics of the respondents are shown in table 1 . All the 1,110 students took part in the study. Ninety-eight percent of the respondents were Kuwaitis.

\section{Prevalence of Self-Medication}

The prevalence of self-medication in this adolescent cohort was $92 \%$ (table 2). The prevalence increased with age from $87 \%$ among 14 -year-old students to $95 \%$ among 18 -year-old. Fourteen-year-old students used significantly less non-prescription medicines than 18 -year-old ( $\mathrm{p}=$ 0.037 ). Sixty-five percent of medicines used were for pain relief, 54\% for respiratory conditions, 39\% for allergic
Table 2. Prevalence of medication use among Kuwait adolescents $(\mathrm{n}=1,110)$

\begin{tabular}{|c|c|c|c|c|c|c|c|}
\hline \multirow[t]{2}{*}{ Therapeutic category of product } & \multicolumn{2}{|c|}{$\begin{array}{l}\text { Prevalence } \\
(\mathrm{n}=1,110)\end{array}$} & \multicolumn{2}{|c|}{$\begin{array}{l}\text { Male } \\
(n=601)\end{array}$} & \multicolumn{2}{|c|}{$\begin{array}{l}\text { Female } \\
(n=509)\end{array}$} & \multirow[t]{2}{*}{$\mathrm{p}$ value* } \\
\hline & $\mathrm{n}$ & $\%$ & $\mathrm{n}$ & $\%$ & $\mathrm{n}$ & $\%$ & \\
\hline All non-prescription medicines & 1,016 & 92 & 539 & 91 & 477 & 94 & $0.047 *$ \\
\hline Pain relief & 718 & 65 & 371 & 63 & 347 & 69 & $0.021 *$ \\
\hline Respiratory & 592 & 54 & 294 & 50 & 298 & 59 & $0.002 *$ \\
\hline Dermatology & 405 & 37 & 196 & 33 & 209 & 41 & $0.003 *$ \\
\hline Anti-allergy & 434 & 39 & 232 & 39 & 202 & 40 & 0.440 \\
\hline \multicolumn{8}{|l|}{ Nutritional supplements and } \\
\hline vitamins & 244 & 22 & 130 & 22 & 114 & 23 & 0.419 \\
\hline Hair products & 160 & 15 & 51 & 9 & 109 & 22 & $<0.001^{*}$ \\
\hline Gastrointestinal & 230 & 21 & 132 & 22 & 98 & 19 & 0.143 \\
\hline Antidandruff & 191 & 17 & 124 & 21 & 67 & 13 & $0.001 *$ \\
\hline Migraine & 139 & 13 & 78 & 13 & 61 & 12 & 0.334 \\
\hline Athlete's foot & 85 & 8 & 66 & 11 & 19 & 4 & $<0.001^{*}$ \\
\hline
\end{tabular}


conditions, $37 \%$ for dermatological conditions, $23 \%$ were nutritional products and vitamins, $21 \%$ were gastrointestinal products, $17 \%$ were antidandruff products, $15 \%$ were hair products, $13 \%$ were medicines for migraine and $8 \%$ were athlete's foot products.

There were significant differences between male and female in the use of certain medications (table 2). Female students more commonly used pain relief, respiratory, dermatologic and hair products than male, while male students used antidandruff and athlete's foot preparations more than female. Male students also significantly used vitamin $\mathrm{A}, \mathrm{B}, \mathrm{C}$ and $\mathrm{E}$ more than female $(\mathrm{p}<0.05)$.

Four hundred and ninety-nine (74\%) of the female students indicated that they used medications to manage menstrual discomfort: 224 (45\%) used paracetamol, 92 (18\%) herbs, $76(15 \%)$ mefenamic acid, 69 (14\%) hyoscine preparations, $41(8 \%)$ aspirin, 30 (6\%) ibuprofen, while $56(11 \%)$ used other products.

Three hundred and two (64\%) of the male students reported that they self-medicated for muscular pain: 151 (32\%) used various creams for rubbing, 140 (30\%) paracetamol, $56(12 \%)$ aspirin, 18 (4\%) ibuprofen, 16 (3\%) diclofenac, and 22 (5\%) used other medications.

\section{Sources of Information on Medication}

A breakdown of the sources of drug information for the adolescents in Kuwait is shown in figure 1. The most common source of general information was parents. For acute illness $57 \%$ of respondents stated that they would seek advice for medications from a doctor, $36 \%$ from their parents, $6 \%$ would follow their own instincts while only $1 \%$ would seek the advice of a pharmacist. Female students were more likely to seek advice from parents while male students were more likely to seek advice from a doctor $(p=0.01)$. A total of $701(64 \%)$ stated that they would like to receive more information on the medication they used.

\section{Discussion}

We acknowledge that this type of study, using a selfadministered questionnaire, is largely dependent upon information given by respondents. Although students were encouraged to complete the questionnaire independently, mutual influence between pupils could not be entirely ruled out. However, given the high level of response, the results should closely approximate the behaviour of the adolescent population in Kuwait.

Self-medication increased with age. This trend has been reported elsewhere [6-9] and may be due to children

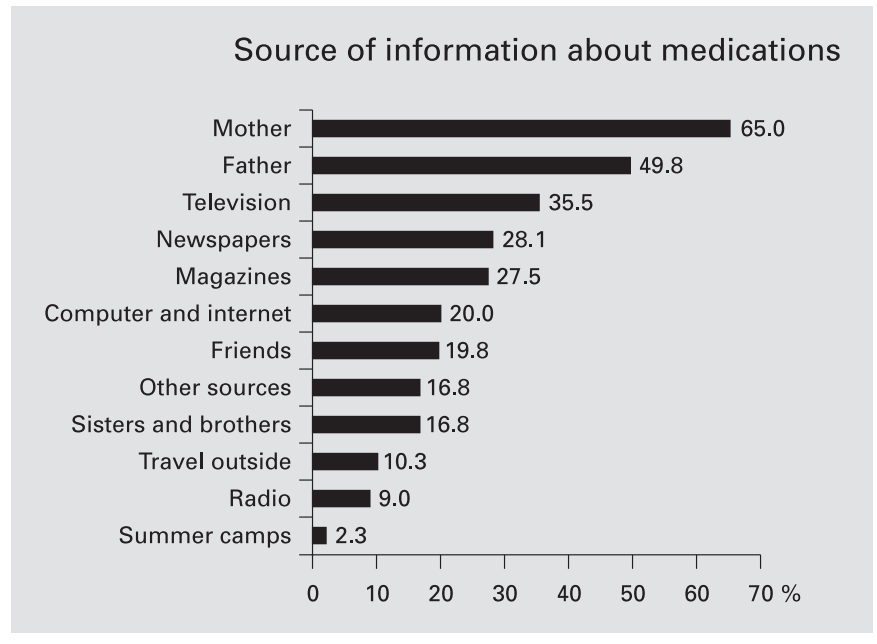

Fig. 1. Source of information on medication among Kuwait adolescents $(n=1,110)$.

becoming more aware of their health needs as they grow older. More female students than male used medicines for pain. This could be explained by the high usage of painkillers for menstrual pain. Male students on the other hand tended to use more of vitamin A, B, C and E than female. Male students also used more products for muscular pain, which may be explained by the fact that they tend to do more physical activities, which often result in sprains and injuries. Gender differences in the use of medicines have also been reported elsewhere [8,9].

Few students consulted pharmacists for information on drugs. In Kuwait, the pharmacist's role is mainly seen as that of a drug salesman rather than that of a health care provider. Patient education and awareness campaigns are necessary to promote the role of the pharmacist in $\mathrm{Ku}-$ wait, particularly because in modern society the pharmacist plays an active role in the provision of drug information. In view of the wide spectrum of drugs available over the counter, it is vital that pharmacists in Kuwait assume this role after appropriate training and with continuing professional development programmes.

\section{Conclusion}

The prevalence of self-medication among adolescents in Kuwait has been shown to be high. Self-medication use tended to increase with age and differed between male and female students. Few adolescents consult pharmacists on drug information. This issue needs to be addressed by the responsible authorities in Kuwait. 


\section{References}

1 World Health Organization: The role of the pharmacist in self-care and self-medication. Report of the 4th WHO Consultative Group on the Role of the Pharmacist. The Hague, 1998. http://www.who.int/medicines/library/ dap/who-dap-98-13/who-dap-98-13.pdf (accessed 21 Aug 2004).

2 Blenkinsopp A, Bradley C: Over the counter drugs: Patients, society and the increase in selfmedication. BMJ 1996;312:629-632.

-3 Bradley C, Blenkinsopp A: Over the counter drugs: The future for self-medication. BMJ 1996;312:835-837.
4 WHO Guideline for the Regulatory Assessment of Medicinal Products for Use in SelfMedication, 2000. www.who.int/medicines/library/qsm/who-edm-qsm-2000-1/who-edm-qsm00_1.htm (accessed 17 Nov 2003).

5 Covington T: Self-care and non-prescription pharmacotherapy; in Popovich NG, Allen LV Jr, Berardi RR, DeSimone EM II, et al (eds): Handbook of Nonprescription Drugs, ed 12. Washington, American Pharmaceutical Association, 2000, pp 1-14.

6 Nicholls PJ, Stevens RG, Albahsain NA: Medication used by Saudi girls. Saudi Pharm J 2002;10:126-132.
7 Tse MHW, Chung JTN, Munro JGC: Selfmedication among secondary school pupils in Hong Kong: A descriptive study. Fam Pract 1989;6:303-306.

8 Hansen EH, Holstein BE, Due P, Currie CE: International survey of self-reported medicines use among adolescents. Ann Pharmacother 2003;37:361-366.

9 Chambers CT, Reid GJ, McGrath PJ, Finley GA: Self-administration of over the counter medication for pain among adolescents. Arch Pediatr Adolesc Med 1997;151:449-455. 